\begin{tabular}{|c|c|c|}
\hline & $\begin{array}{c}\text { PORTSAID ENGINEERING RESEARCH JOURNAL } \\
\text { Faculty of Engineering - Port Said University } \\
\text { Volume17 No. 1pp: 8:12 }\end{array}$ \\
\hline
\end{tabular}

\title{
EVALUATION OF THE BUILT-UP WELD FORMED COMPONENT USING SUBMERGED ARC WELDING
}

\author{
Ebtisam F. Abdel-Gawad ${ }^{1}$
}

\begin{abstract}
The built-up welding technology is a specialized process, which has many applications in welding industry. A single electrode submerged arc welding is applied to deposit a thick weld metal layer on a dummy low carbon steel plate for shaping a bulk component, which is approximately all weld metal. Failure occurs rarely in service, and initiates at a notch like defect. Present work aims at evaluating the effect of notch geometry with different sharpness at different loading rates on the tensile properties of steel weld formed built-up multi layers component using the submerged arc welding. In addition, the behaviour of such a component during room temperature impact loading at different notch orientations is evaluated. Besides, weld homogeneity is studied through hardness measurements. The results indicate that, steel weld formed built-up multi layers component is sensitive in tensile loading to both high loading rates, and the presence of sharp notches (like defects), and insensitive to the orientation of notches under room temperature impact loading. Moreover, isotropy of weld structure is indicated through the regularity of hardness measurements.
\end{abstract}

Keywords:Built-up welding, Submerged arc welding, Rate of loading, Notch sharpness

\section{INTRODUCTION}

The built-up welding technology is important in many applications such as shape welding, repairing, and surfacing. In shape welding components are produced entirely from weld metal. Shafts, large boilers, shell rings, and flanges using welding around a horizontal axis, and spherical caps using welding around a vertical comparative axis are some examples of shape welding applications [1-4].

Repairing of components damaged by wear, cracks, or similar are treated by removing the damaged material and applying new material by the built-up all weld metal technology, followed by machining to the correct geometry. There is no need to keep numerous spare parts when worn parts can be rebuilt [5-7].

In surfacing two functional processes are included, hard facing and cladding [8-9]. It is known that, bulk components, such as, rotors show bad running behaviour in Babbitt bearings. Therefore, it is necessary to apply weld hard facing by overlay the journal areas of such rotors with materials, which improve their performance. Such materials are applied normally by built-up welding technology. Meanwhile, several components, for example, rotors are in operation for long periods, with overlay welded journal areas, as well as overlay welded horizontal shaft seal sections, without experiencing any problems. Similar welds are used in repair welding, while dissimilar welds are used in hard-facing (wear protection) or cladding to provide protection from corrosive and erosive metal loss environments. To form final components, filler metals are deposited on the substrate body described as build up welding. In principle, all weld metals are performed using welding process of a high rate of deposition, such as submerged arc welding (SAW). Robot systems and CNC machines, as advanced technologies, are recently the key for the production of all weld metal components.

${ }^{T}$ Associate professor, Production Engineering and Mechanical Design Department, Faculty of Engineering, Port Said University
In addition to the adequate mechanical properties required in the weld formed by built-up welding (such as good running performance or erosion / corrosion resistance in dry and wet environment), as they differ from those of the substrate base material, it had to be taken into account, whether the weld formed affects the structural strength of the whole component. Notches, also, cannot be avoided in many structures and machines and fracture that created by a sharp notch often happens rather quickly due to the concentration of stresses at this local area [10-11], therefore understanding their effect is of key importance in weld formed built-up welding.

Steel tensile properties are usually determined at relatively slow loading rates to obtain appropriate design information at static loads. Tensile properties of components subjected to high loading rates, such as those of impact loads, may be varied [12-13]. Such behaviour, which differs for different materials, needs further investigation. Present study concentrates attention for deeper knowledge; how the built-up welding technology can achieve adequate mechanical properties when shape welding a component entirely from ordinary structure steel. Also, the investigation focuses on notch sharpness effect on the weld formed built-up welded component in static tension loading at different high loading rates (cross head speeds), and also in impact loading besides evaluation of hardness across the weld formed built-up welded component.

\section{EXPERIMENTAL DETAILS}

\subsection{Materials}

The initial base material shown in Fig.(1) used as a dummy body, was as-rolled ship building steel plate St.42 (700 x 450 × $20 \mathrm{~mm})$. Multi layers-all weld metal is deposited on the dummy base plate to form the final experimental model with the configuration shown in Fig. (2). Chemical composition using spectrum analysis for both the dummy plate and the built up weld deposited on 
it are presented in Table (1).

\begin{tabular}{|c|c|c|c|c|c|c|}
\hline Element \% & $\mathrm{C}$ & $\mathrm{Mn}$ & $\mathrm{Si}$ & $\mathrm{P}$ & $\mathrm{S}$ & $\mathrm{Fe}$ \\
\hline $\begin{array}{c}\text { Dummy } \\
\text { base plate } \\
\text { St.42 }\end{array}$ & 0.238 & 0.881 & 0.141 & 0.10 & 0.027 & 98.6 \\
\hline $\begin{array}{c}\text { Multi- } \\
\text { layers weld } \\
\text { formed }\end{array}$ & 0.079 & 1.700 & 0.337 & 0.024 & 0.008 & 97.68 \\
\hline
\end{tabular}

Table 1 Chemical composition of the dummy plate and the multi-layers weld

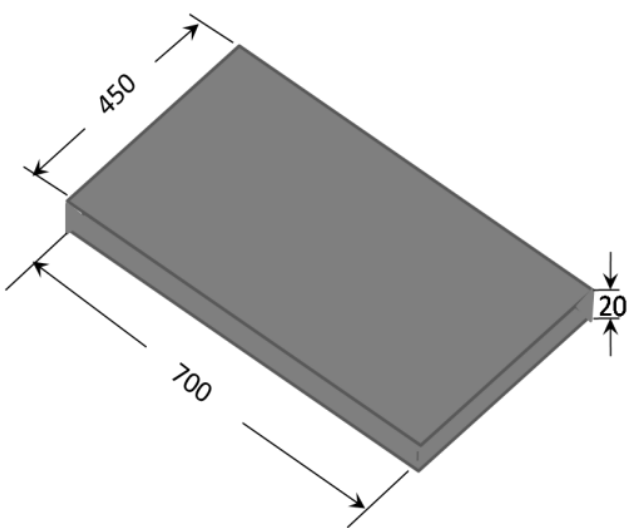

Fig. 1: Shape and dimensions of the Dummy base plate

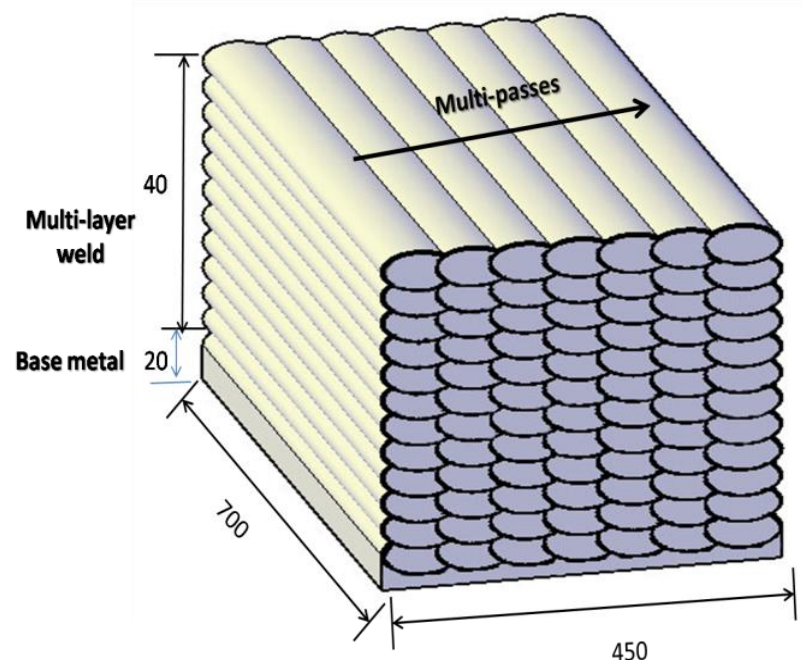

Fig. 2: Configuration of pre-determined built-up experimental model

\subsection{Experimental Procedure}

The used welding machine for the preparation of the experimental model is a single electrode automatic submerged arc welding - ESAB - A6T tractor type machine. The recommended welding parameters with a solid wire listed in Table (2) are applied. Multi-passes with $1 / 3$ bead overlap are laid in axial direction. Bead overlap applies to induce regular layers. Twelve weld layers deposit on the dummy base plate to reach a final thickness of $40 \mathrm{~mm}$, and the heat input during the welding operation is around $2.5 \mathrm{KJ} / \mathrm{mm}$.
Table 2 Applied welding parameters

\begin{tabular}{|c|c|}
\hline Welding Parameter & Data \\
\hline Welding Process & Submerged Arc Welding \\
\hline Welding Voltage & 32 Volt \\
\hline Welding Current & 550 Ampere \\
\hline Polarity & DCEN \\
\hline Welding Speed & $1 / 3$ (weld bead) \\
\hline Weld bead overlapping & $5 \mathrm{~mm}$ \\
\hline Wire Diameter & gravity (flat) \\
\hline Welding Position & O K Autrod 12-10 (DIN \\
\hline Welding Wire & OK Flux 10-70 (DIN 32522) \\
\hline Welding Powder &
\end{tabular}

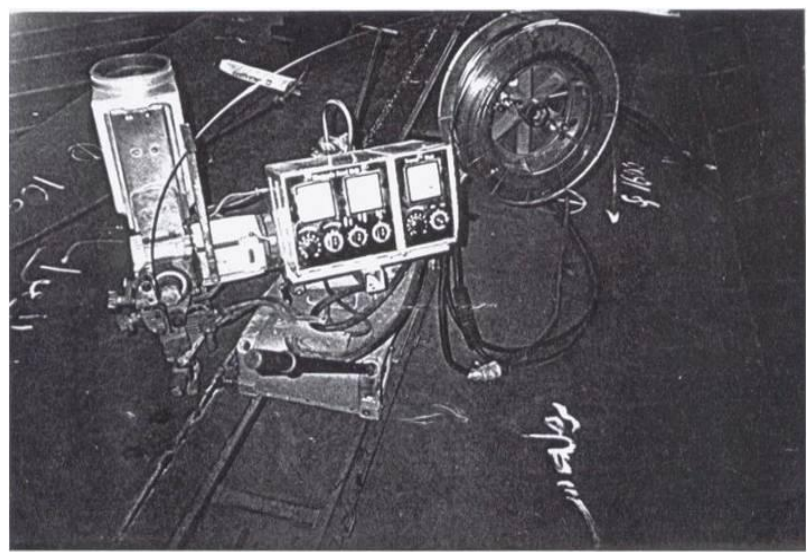

Fig. 3 closed up view of submerged arc welding machine

\subsection{Specimens Cutting Plan}

After weld completion, notch effect is investigated under static and impact loadings. So, short tensile test specimens with and without notch is machined from the built up all weld metal. Notches with various sharpness are located at the middle of the tensile specimens, as shown in Fig. (3). Charpy impact specimens with notch parallel to weld surface or parallel to weld thickness are also cut from the built up all weld metal in welding and transverse directions.

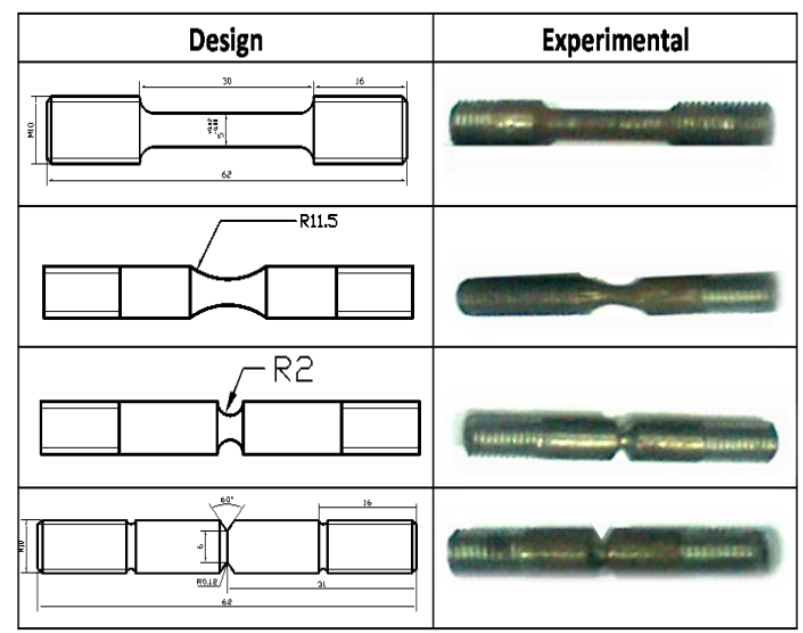

Fig. 4: The smooth and notched tensile specimens extracted from multi-layers all weld metal 


\subsection{Testing Procedure}

A tensile testing machine of 40 Tons capacity is used to test smooth and notched tensile specimens at different crosshead speeds $(5,10$, and $15 \mathrm{~mm} / \mathrm{min})$. Tensile strength and ductility (as percentage elongation), are recorded for the smooth specimens, and notch tensile strength, ductility, and notch strength ratio are recorded for the notched specimens with various notch geometry and sharpness. Moreover, impact test is performed at room temperature for Charpy specimens with different orientations. Brinell hardness testing is performed across the experimental model region, and along the weld formed multi-layers. Typical tension test records are shown in Fig. (4).

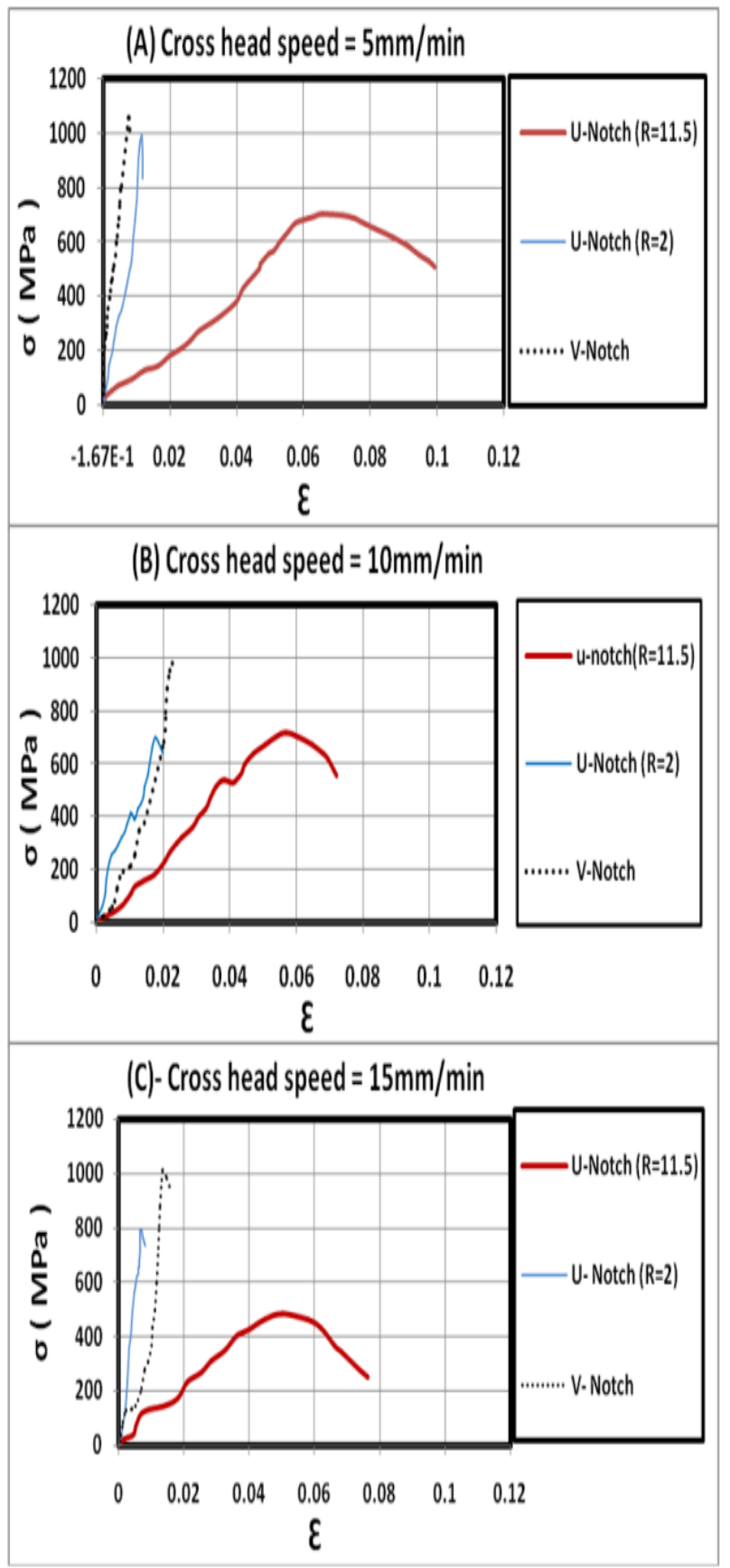

Fig. 5: Stress-strain records at different cross head speed and notch geometry

\section{RESULTS AND DISCUSSIONS}

\subsection{Notch Tensile Behaviour}

In general, the presence of notches in weld formed multilayers specimens causes notch strengthening compared to smooth specimens. For a given crosshead speed (e.g., $5 \mathrm{~mm} / \mathrm{min}$ ), it is observed that, with sharper notch, the tensile strength increases. This is true for all investigated speeds, as shown in Fig. (5). Strengthening can be explained in view of two phenomena [14]. First, the creation of tri-axial tensile stresses at the root of the notch leads to suppress plastic deformation. Second, non-uniformity of stresses and strains at the notched cross section weakens the test specimen, otherwise stress is concentrated at the notched area. Thus, the tensile strength increases, and the weld formed multi-layers specimens behave in a brittle manner.

Tensile testing is conducted on both the weld formed multi-layers notched specimens, and the smooth specimens at three loading rates 5,10 , and $15 \mathrm{~mm} / \mathrm{min}$. Interrelated effect of loading rate and notch geometry on the notch strength, results in a loss in tensile strength with increasing loading rate. For U-notch test specimens ( $\mathrm{R}=2 \mathrm{~mm}$ ) the tensile strength decreases from 970 to 800 and $706 \mathrm{MPa}$ with increasing the loading rate from 5 to 10 , and to $15 \mathrm{~mm} / \mathrm{min}$, respectively. This is true for all investigated notch geometries, as shown in Fig. (5). On the other hand, smooth specimens are approximately insensitive to the change of loading rate.

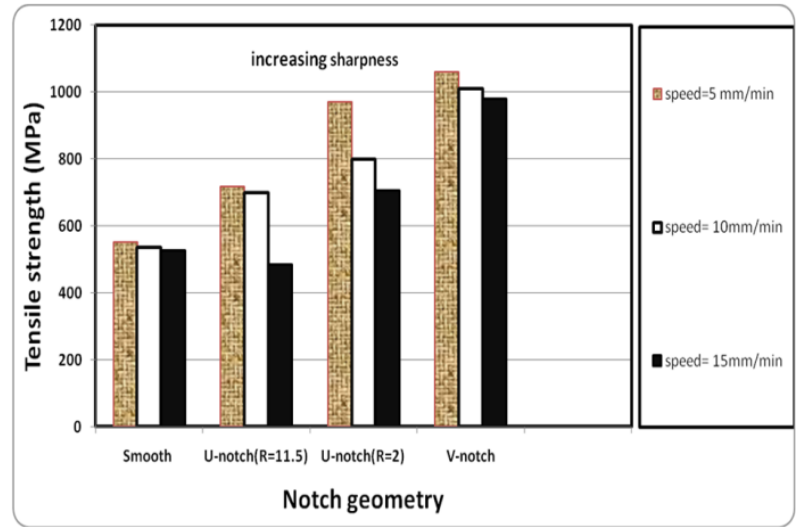

Fig. 5: Effect of cross head speed and notch geometry on notch tensile strength

Notch strength ratio (NSR) is the ratio between tensile strength of notched specimen and that of un-notched specimen. It is calculated for various loading rates and notch geometries and presented in Fig. (6). Generally, NSR is more than unity for all notch geometries at all applied loading rates, except the highest loading rate with lowest notch sharpness (U-notch and $\mathrm{R}=11.5$ ). At sharpest notch geometry (V-notch), NSR reveals highest values and decreases with decreasing notch sharpness ( $u-$ notch at $\mathrm{R}=2$, and $\mathrm{u}$-notch at $\mathrm{R}=11.5$ ). At the sharpest notch (V-notch), the metal is insensitive to loading rates (5, 10 and $15 \mathrm{~m} / \mathrm{min})$ and becomes sensitive at lower notch sharpness.

Ductility of the weld formed multi-layers, measured as percentage elongation, tends to decrease with increasing notch sharpness. This refers to suppression of plastic 
deformation with increasing notch sharpness, which leads to a brittle behaviour of the specimen.

The increase in cross head speed causes a slight increase in ductility at smooth and low notch sharpness specimens (U-notch, $\mathrm{R}=11.5$ ). At higher notch sharpness (U-notch, $\mathrm{R}=2 \mathrm{~mm}$, and $\mathrm{V}$-notch), the ductility is almost insensitive, Fig. (7). This can be explained in view of the short time involved at higher notch sharpness for developing plastic deformation.

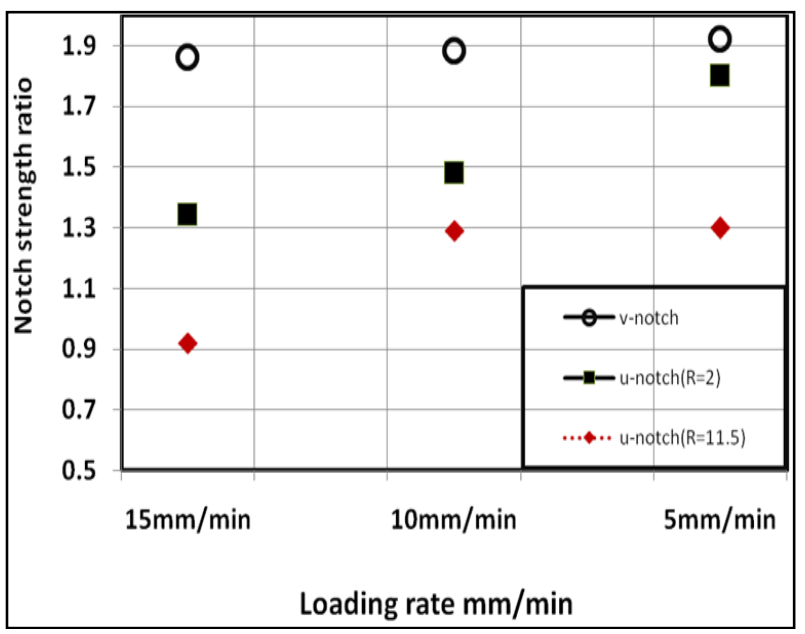

Fig. 6: Notch strength ratio NSR at various crosshead speeds for different notch sharpness

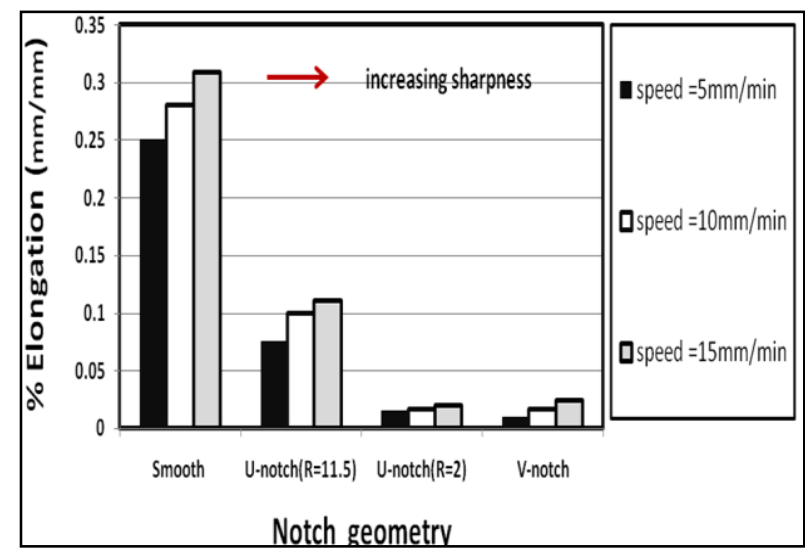

Fig. 7: Effect of cross head speed and notch sharpness on ductility

\subsection{Notch Impact Behaviour}

Results of impact testing at room temperature indicate that, the absorbed impact energy of weld formed metal specimens is not affected significantly by notch orientation. The absorbed impact energy is in the range 142 and 146 Joule, as indicated in Fig. (8). This may be due to homogeneity and isotropic properties of the weld formed experimental model. This may imply structure modification of sub layers by the deposited layers.

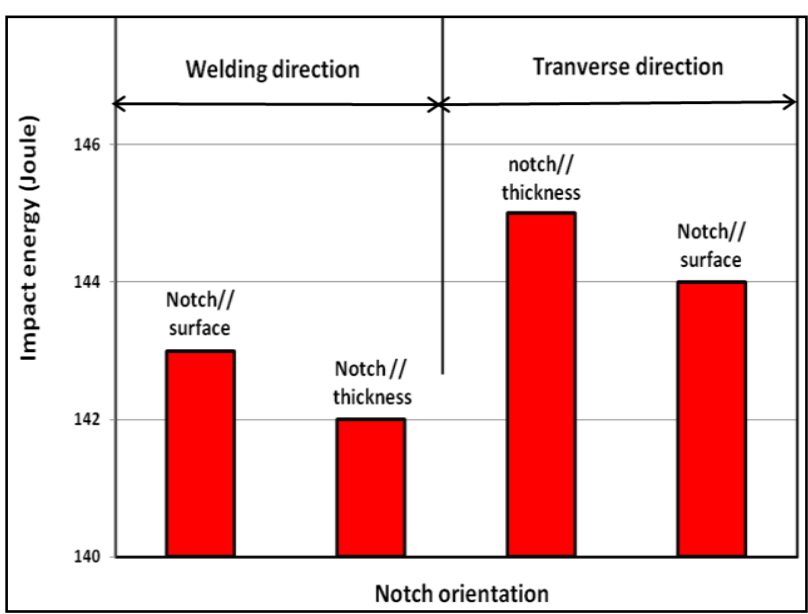

Fig. 8: Absorbed impact energy vs. notch orientation

\subsection{Hardness and Macrostructure}

The weld formed multi-layers specimens are prepared for hardness measurement and macroscopic examination, with successively finer grades of silicon carbide papers (up to 1200 grit), polished using diamond paste, and then etched with Nital (3\% NHO3). Brinell hardness distribution across the weld formed component regions is shown in Fig.(9). Hardness of the weld formed sub layers is in the range 174 to $180 \mathrm{HB}$, while a higher hardness value of $185 \mathrm{HB}$ is at the top layer. This could be due to tempering of the sub-layers by repeated thermal cycles. It is observed that, the average hardness at the weld formed multi layers $(177 \mathrm{HB})$ is higher than that of the dummy base plate $(150 \mathrm{HB})$. Due to the increase in hardness by applying the built-up welding technology, an improvement in wear resistance may be expected.

The hardness distribution along the weld formed multilayers $20 \mathrm{~mm}$ below the top surface is shown in Fig.(10), which reveals almost the same hardness. This can be attributed to exposure of the weld formed metal to the action of multi-thermal cycles caused by the multipasses, which refines and homogenize the structure of the weld formed metal.
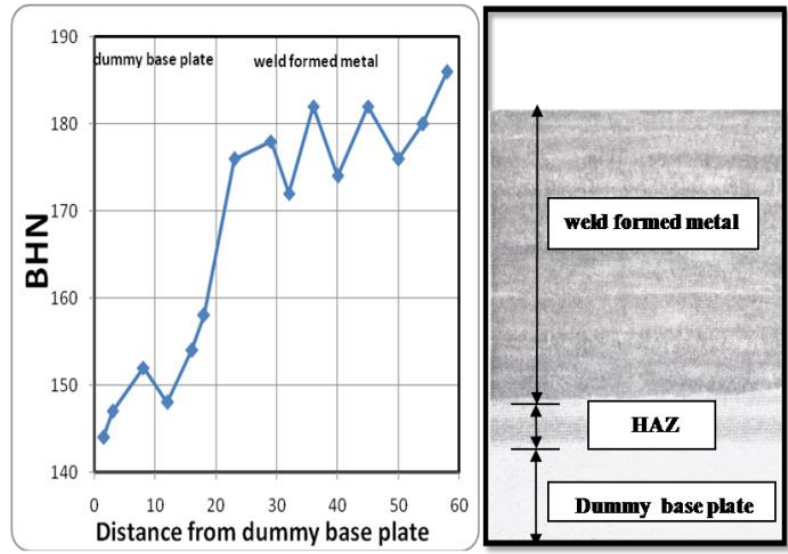

Fig. 9: Hardness measurement across regions of the weld formed built-up component 


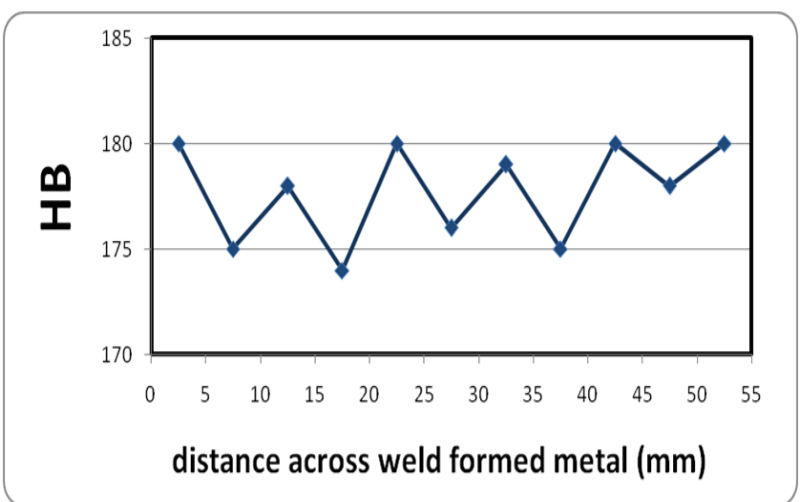

Fig.10: Distribution of hardness along the weld formed multi-layers

\section{CONCLUSIONS}

Based on present experimental results, the following could be concluded:

1. Notch tensile properties of the weld formed multilayers depend not only on geometry and sharpness of defect like notch, but also on the rate of loading.

2. The sharper is the notch; the higher is the notch tensile strength and the lower the ductility of the weld formed metal.

3. High loading rates have a great negative effect on notch tensile strength in presence of sharp notches rather than in presence of lower notch sharpness.

4. Notch orientation does not significantly affect the impact energy of weld formed metal.

5. The hardness of the weld formed metal is higher than that of the dummy base metal.

6. The weld formed metal using the built-up welding technology is of a homogeneous structure and high hardness.

\section{ACKNOWLEDGMENT}

The present study was sponsored by faculty of engineering, port-said university, Egypt. The authorswish to express their sincere thanks to Port-Said ship yard for help in delivering the materials and production of the experimental model.

\section{REFERENCES}

[1] Prinz et al, "Method And Apparatus for Fabrication Of Three Dimensional MetalArticles By Weld Deposition", US Patent Number 5-207-371, May (1993).

[2] Material\& Welding Consultant Team:"Manufracturing of component parts by shape welding", Research, Development, Design, and Manufacture, Am Grafenbusch 46 D-46047 Oberhausen, http://radona.de/shapeweld.htm

[3]DIN 1910 "Welding": "Surfacing and Shape Welding", ISF, Aachen, (2005).

[4] T. Demler and W. Issler: "Reliability engineering", Special report, the IAEA Bulletin, Vol.25 No.3, September (1983).

[5]S. V. GUPTE: "Inspection and Welding Repairs of Pressure Vessel Inspector (API510)", (CCOE Paint and Coating Inspector (Pressure Vessels Nace India).
[6]Dumitru-TitiCicici, Gheorghe Solomon: "Researches Regarding Quality Of The WeldedJoints Obtained By Applying The Techniques Of Welding Renewal To Components FromThe Energy Industry", Made From Sa 387 Gr 12", U.P.B. Sci. Bull., Series D, Vol. 71,Iss. 3, (2009).

[7]Issler, S.; Klenk, A.; Shibli, A.A.; Williams, J.A.: "Weld repair of ferritic weldedmaterials for high temperature application", International Materials Reviews, Vol. 49, No.5, (2004).

[8]Steffen Nowotny, Siegfried Scharek,: "Laser Beam Build- Up Welding: Precision inRepair, Surface Cladding, and Direct 3DMetal Deposition", ASM International, February 9, (2007).

[9]JánVin|váš ，Janette Brezinová ,Anna Guzanová : "Evaluation of the quality ofcladding deposited on continuous steel casting rolls", International Journal of MaterialsResearch, August (2012).

[10]S. K. Nath and Uttam Kr Das: "Effect Of Microstructure And Notches On TheFracture Toughness Of Medium Carbon Steel",Journal of Naval Architecture and Marine Engineering, 3(2006).

[11] C.P. Wua, L.W. Tsay b, C. Chen: "Notched tensile testing of T-200 maraging steel and its laser welds in hydrogen", Materials Science and Engineering, A346 (2003).

[12] Tan, KianSing:"Dynamic Loading Characteristics in Metals and Composites",Master's Thesis, NavelPostgraduate School Monterey, California, December (2009).

[13]Roger L. Brockenbrough, P.E.: "Properties Of Structural Steel And Effects OfSteelmaking And Fabrication", Chapter 1, R. L. Brockenbrough\& Associates, Inc,Pittsburgh, Pennsylvania.

[14] W.F.Brown, Jr,and George Sachs: " A critical review Of Notch Sensitively In Stress-rupture Tests", Lewis Flight Propulsion laboratory,(NASA), Washington, August, (1951). 